\title{
Seismic Ground Motion Amplifications Estimated by Means of Spectral Ratio Techniques: Examples for Different Geological and Morphological Settings
}

\author{
M. Massa ${ }^{1}$, S. Lovati ${ }^{1}$, S. Marzorati ${ }^{2}$ and P. Augliera ${ }^{1}$ \\ ${ }^{1}$ Istituto Nazionale di Geofisica e Vulcanologia, Sezione Milano-Pavia, Milano \\ 2Istituto Nazionale di Geofisica e Vulcanologia, \\ Centro Nazionale Terremoti, Passo Varano (Ancona),
}

Italy

\section{Introduction}

One of the most important issue in seismic hazard and microzonation studies is the evaluation of local site response (i.e. the tendency of a site to experience during an earthquake greater or lower levels of ground shacking with respect to another). In general site effects reflect all modifications (in amplitude, frequency content and duration) of a wave-field produced by a seismic source during the propagation near the surface, due to particular geologic (stratigraphy and morphology), geotechnical (mechanical properties of deposits) and physical (e.g. coupling of incident, diffracted and reflected seismic waves) conditions of a particular site.

Actually local seismic amplification represents one of the main factors responsible for building damage during earthquakes: this statement is supported by well documented evidences of structural damages during past moderate to high energy events occurred both in Italy (e.g. 23 th November 1980, Mw 6.9, Irpinia earthquake, Faccioli, 1986; 26 th September 1997, Mw 6.0, Umbria-Marche earthquake, Caserta et al., 2000; the 31th October 2002, Mw 5.7, Molise earthquake, Strollo et al., 2007; 6th April 2009, Mw 6.3, L'Aquila earthquake, Cultrera et al., 2009) and in other worldwide countries (e.g. 3rd March 1985, Mw 7.8, Chile earthquake, Celebi, 1987; 17th August 1999, Mw 7.6, Izmit earthquake, Sadik Bakir et al., 2002). For this reason the site effects evaluation, performed by experimental methods but also through numerical simulations, has attracted the attention of engineering seismology and earthquake engineering communities. Of consequence, in the last decade many experiments were performed in correspondence of different setting such as alluvial basins (Parolai et al., 2001 and 2004; Ferretti et al., 2007; Massa et al., 2009; Bindi et al., 2009) or topographies (e.g. Pischiutta et al., 2010; Massa et al., 2010; Buech et al., 2010; Marzorati et al., 2011; Lovati et al., 2011).

The present work has the aim to evaluate the capabilities of the most common passive methods at present used in seismology to evaluate the site response: HVSR (Horizontal to Vertical Spectral Ratio technique on seismic noise, Nakamura, 1989, or earthquakes, Lermo \& Chavez Garcia, 1993) and SSR (Standard Spectral Ratio, Borcherdt, 1970). The reliability of 
the considered techniques was evaluated by comparing the results obtained analysing different seismic signals (noise, local earthquakes and teleseisms) recorded in different geological and morphological setting and by using different instrumentation (weak motion and strong motion sensors).

In order to obtain the aforementioned scope, 5 Italian test sites housing, at present, a seismic station (permanent and temporary networks) managed by Italian National Institute for Geophysics and Volcanology [INGV], were selected. The site selection was performed in order to evaluate possible local site effects in different conditions: stations numbered as 1 and 2 (figure 1) are located in the centre of the Po Plain and in correspondence of its edge respectively, station 3 represents a station that, being installed in the central Alps, could in general represent a reference site, while two stations (4 and 5, figure 1$)$ are installed at the top of topographies, the first located in North-Est Italy and the second, more characterized by a clear 2D configuration, in the central Apennines respectively.

It is worth noting that in correspondence of areas characterized by a low rate of seismicity, but potentially able to suffer energetic seismic events (Gruppo di Lavoro CPTI 2004, http://emidius.mi.ingv.it/CPTI/), such Northern Italy, the capability of different techniques to estimate local response, also evaluated using different type of instruments, might represent a fundamental step in order to avoid some practical problems such as long in time field experiments due to the lack of recordings related to local events (e.g. noise measurements or analyses on teleseisms might be able to provide good results in particular frequency ranges). In any case, the results coming from spectral analysis, in particular if they are obtained without a reference site, have to be always read combined to other detailed geological, geothecnical and geophysical information related to the investigated site (stratigraphy, shear wave velocity etc.).

\section{Geological and geomorphological settings}

In order to highlight the capabilities of the considered spectral technique to estimate the site response, sites characterized by geological and/or geomorphological setting were selected. The sites were selected both in Northern (station 1, 2, 3 and 4, see figure 1 and 2) and central Italy (station 5, see figure 2).

The site where station 1 is installed (figure 1, top) is located in the foreland of the CentralAlps, in correspondence of morainic deposits with depth of dozen of meters (Regione Lombardia, 2003). The site where station 2 (figure 1, middle) is installed is located in the central area of the Po Plain, one of the more extended alluvial basin at global scale (surface of about $46.000 \mathrm{~km}^{2}$ ) characterized by thickness of deposits up to some kilometers (Regione Lombardia, 2003). Stations 3 (figure 1, bottom) and 4 (figure 2, top) are installed in correspondence of stiff formations: site 3, located in the Central Alps (about $800 \mathrm{~m}$ of quota) is characterized by the presence of massive limestone (and/or dolomite, Regione Lombardia, 2002), while site 4, even if from a stratigraphical point of view is characterized by compact sandstone and clay (sheet 037 of the 1:100.000 Geological Map of Italy), represents an interesting case study being the station installed at the top of a hill. Station 5 (figure 2, bottom) is installed at the top of a very steep ridge chracterized by a pronunced 2D morphology. From a geological point of view the site is characterized by massive limestone formation (sheet 138 of the 1:100.000 Geological Map of Italy; Amanti et al., 2002). The areas surrounding the ridge at NE of the ridge is characterized by alluvial, lacustrine and fluvial deposits that overlap locally the limestone massif. 
In Bordoni et al. (2003), on the base of the geological information of the 1:500.000 Italian Geological Map, the authors classified the Italian territory following the provision reported in the Eurocode8 (CEN, 2004). For the considered site, the errors associated to the 1:500.000 scale have been checked by comparing this map with very detailed geological maps (scale 1:10.000 and 1:5.000, figure 1, right panels). From such a comparison no significant differences has been observed. On the basis of this classification (after adopted also in the new Italian code for buildings NTC, 2008) site 3, 4 and 5 are included in A soil-category $(\mathrm{Vs} 30>800 \mathrm{~m} / \mathrm{s})$, station 1 is include in B soil-category $(360<\mathrm{Vs} 30<800 \mathrm{~m} / \mathrm{s})$ and station 2 is included in C soil-category (Vs30 $<360 \mathrm{~m} / \mathrm{s}$ ). Moreover, following NTC, 2008, site 4 and 5 are included in T2 (average slope $\left.>15^{\circ}\right)$ and T3 $\left(15^{\circ}<\right.$ average slope $\left.<30^{\circ}\right)$ topographiccategory respectively.
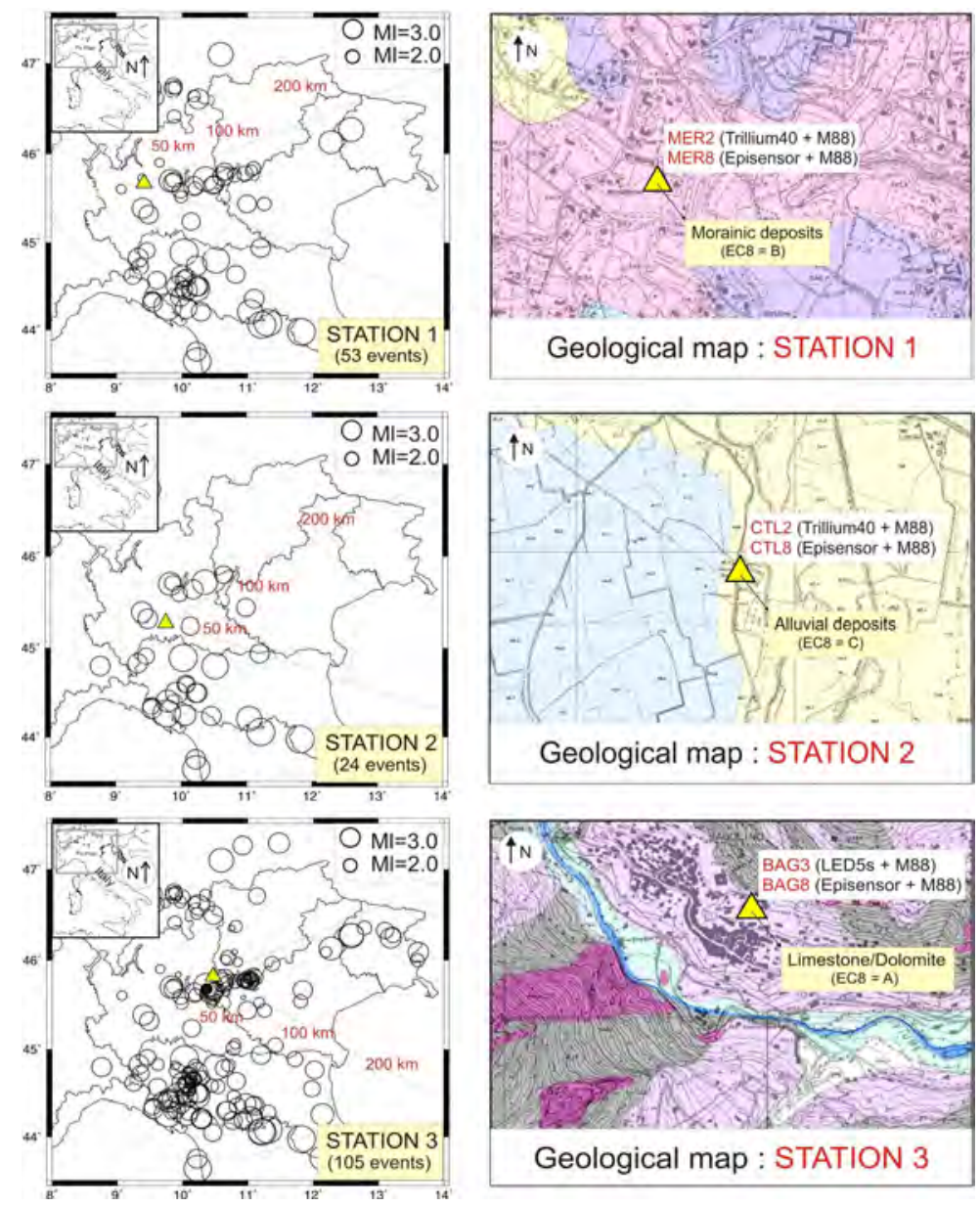

Fig. 1. Sites selected for the analyses (yellow triangles): on the left panels circles represent weak-motion $\left(\mathrm{M}_{\mathrm{L}}\right.$ between 2.0 and 3.0) recorded at each site (53 for station 1, 24 for station 2 and 105 for station 3 ). In the right panels the relative geological maps are reported. 

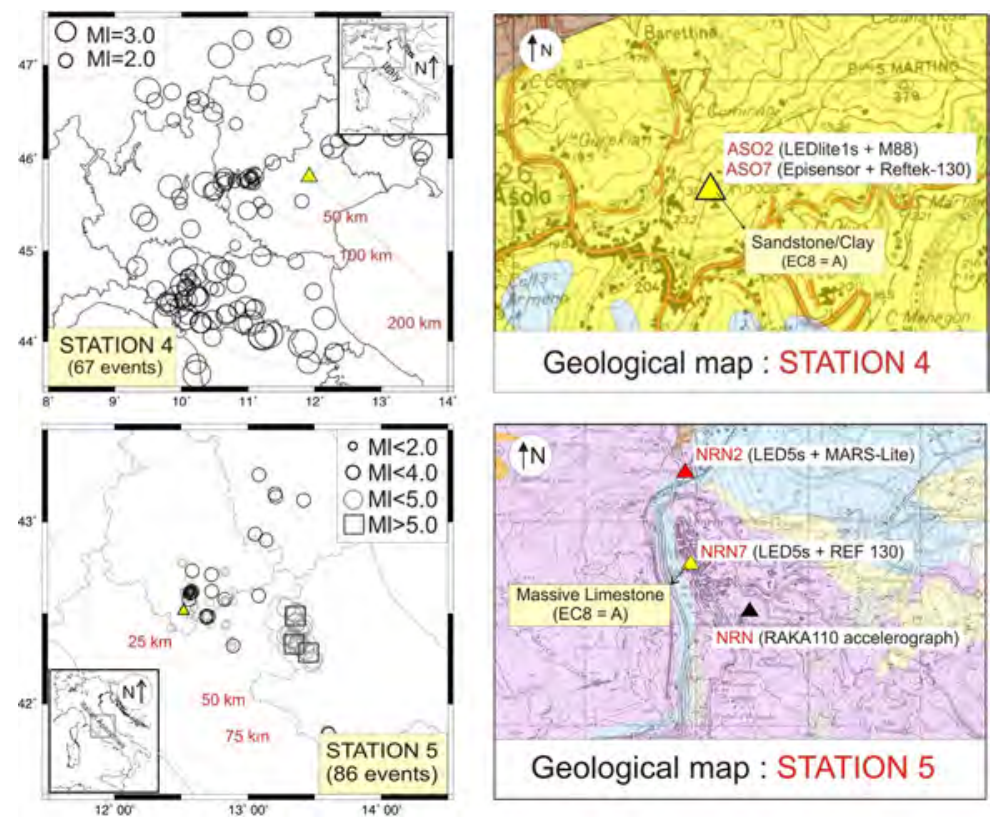

Fig. 2. Sites selected for the analyses (yellow triangles). Top panels: as explained in figure 1 but for station 4 (67 events), located at the top of a topography. Left bottom panel: data set available for station 5 (circles are 29 events with $M_{L}<4$ and squares are 12 events with $M_{L \geq}$ 4). Right bottom panel: geological map and available stations (in red the reference site, used for SSR analyses, in black the permanent RAN strong-motion station).

\section{Data set and data processing}

For the analyses a relevant data set collected in the last 5 years was taken into account (Figure 1 and 2 left panels). It is composed by microtremor recordings, local events occurred in Northern and central Italy ( $\mathrm{M}_{\mathrm{L}}$ up to 5.3 and epicentral distance up to $200 \mathrm{~km}$ ) and teleseisms.

Stations 1, 2, 3 and 4 (Figure 1 and 2, right panels) belong to the permanent strong motion network of Northern Italy (RAIS, http://rais.mi.ingv.it). They are equipped both with strong-motion (Kinemetrics Episensor FBA ES-T) and velocimetric sensors (broad band Trillium 40s for station 1 and 2, semi broad-band Lennartz LE3D-5s for station 3 and short period Lennartz LE3D-1s for station 4). Station 5 (NRN7, see figure 2), located at the top of Narni ridge (central Italian Apennines) belongs to a temporary velocimetric array, composed by 10 stations, installed in correspondence of the ridge and surroundings in the period March-September 2009 (Massa et al., 2010; Lovati et al., 2011). In this study, in order to make considerations about SSR technique, the station NRN2, located at the base of the ridge (red triangle in figure 2) was considered as reference site. In figure 2 also the location of the permanent RAN (Italian Accelerometric Network, www.protezionecivile.gov.it) strong-motion station installed at the top of the ridge (NRN, black triangle in figure 2) is indicated. All selected stations are equipped by 20 or 24 bits recording systems (Lennartz Mars88 and Reftek 130 respectively). The sampling rate range from $100 \mathrm{sps}$ to $125 \mathrm{sps}$. 
The selection of stations characterized by different type of sensors allows us to record in a wide dynamic range of amplitude: indeed, while on one hand, a weak motion sensor assures high quality records related to seismic background noise, local earthquakes of low magnitude and teleseismic events, on the other hand the strong motion sensor avoids the loss of recordings in the case of high magnitude events with epicenter close to the stations.

Data processing was computed following standard procedures that include: mean removal (on the whole signal), baseline correction (least square regression), removal of instrument response by deconvolution with the instrument response curve (for strong-motion sensors computed just for NRN, being the RAN strong-motion sensor analogue, Massa et al., 2010) also in the case of analogue instrument), time domain cosine tapering (5\%), selection of high and low pass filter (band-pass Butterworth 4 poles). Considering the recorded signal the low-pass frequency were set at $30 \mathrm{~Hz}$ while the high pass cut off was choosen by a visual inspection of data considering both the magnitude of the sensor of the station. Noise recordings were in general windowed in time series of $60 \mathrm{~s}$ (in case of semi broad band stations) or $120 \mathrm{~s}$ (in case of broad band stations) length, while for local events different portion of S-phase ( $5 \mathrm{~s}, 10 \mathrm{~s}, 15 \mathrm{~s}$ starting from the $S$ onset) and $20 \mathrm{~s}$ of coda were considered. Finally, teleseismic events were analysed considering $80 \mathrm{~s}$ windows length selected on both Pn and Sn phases. For all considered signals, for each time window the FFT was calculated and then smoothed using the Konno \& Ohmachi (1998) window ( $b=20)$. In order to detect possible polarization effects, in particular for 2D configurations, the NS and EW horizontal components of ground motion were clockwise rotated of $180^{\circ}$, by step of $5^{\circ}$.
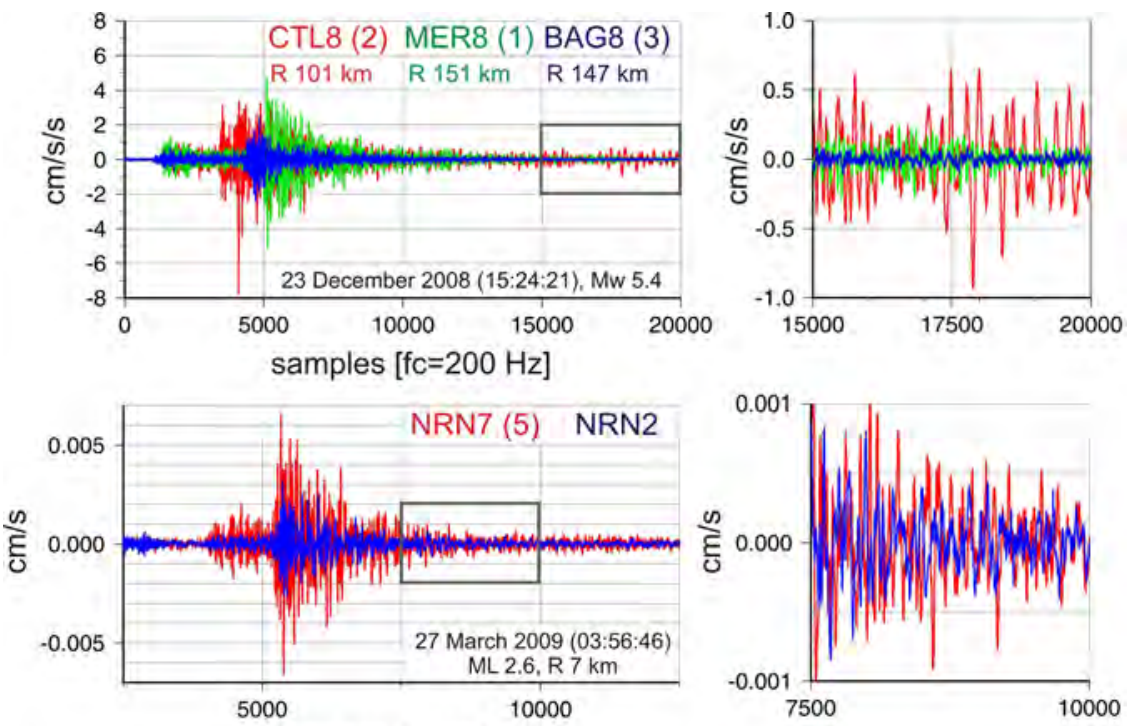

samples $[\mathrm{fC}=100 \mathrm{~Hz}]$

Fig. 3. Top left panel: waveforms of $23^{\text {rd }}$ December 2008, Mw 5.4, Parma earthquake recorded by station 1 (green), station 2 (red) and station 3 (blue). On the right a more detailed image of coda waves. Bottom left panel: waveforms of a weak motion of $\mathrm{M}_{\mathrm{L}} 2.6$ (epicentral distance $7 \mathrm{~km}$ ) as recorded at Narni ridge by station 5 (red) and by the reference one (blue). Also in this case on the right is reported a detailed of coda amplitudes. 
The processed signals were analyzed applying the single station Horizontal to Vertical Spectral Ratio technique (HVSR), both on noise (Nakamura technique, Nakamura, 1989) and earthquakes (Lermo \& Chavez Garcia, 1993) and, also for station 5 (availability of a reference site), the Standard Spectral Ratio technique (SSR, Borcherdt, 1970).

In the top panels of Figure 3 an example of waveforms related to the $23^{\text {th }}$ December 2008, Mw 5.4, Parma earthquake as recorded by stations 1, 2 and 3 is illustrated: it is possible to appreciate the difference both in peak ground acceleration (PGA) between station 3 (blue), located on hard rock, and the others installed on alluvial (station 2, red) and morainic (station 1, green) deposits respectively and, in particular the amplitude of surface waves affecting the station (2) installed in the middle of the Po Plain (red in the top right panel). In the bottom panels of figure 3, weak motion waveforms $\left(\mathrm{M}_{\mathrm{L}} 2.6\right)$ as recorded at Narni ridge by the station 5 (at the top, NRN7 in red) and by the reference station (at the base, NRN2 in blue, see figure 2) are reported. Even in this case, the right panel shows, as for coda waves, the amplitudes recorded at the station installed at the top appear to be higher than those recorded at the base (even if less evidence with respect to the S-phase amplification).

\section{Experimental techniques for seismic site response evaluation}

The evaluation of local seismic site response is usually estimated through different spectral techniques applied both on background noise and earthquakes data. In an optimal condition the operator has the possibility to integrate results coming from different approaches in order to assure reliable responses in a broad range of frequencies. Unfortunately this condition is usually an exception due to the lack of earthquake recordings (especially in areas characterized by low seismicity rate), unavailability of reliable reference site or very high level of background noise (low signal to noise ratio). The main scope of the studies concerning site effects is to identify the fundamental frequencies of a site and, if possible, to provide the related amplification factor. A careful knowledge of the resonance frequency of a soil, coupled to the information about the predominant period of a structure can give a reliable idea of potential damages that we can expect for a site in case of an earthquake (in particular if the predominant frequency of the source reflects that detected for the site of interest). Nowadays in seismology the more commonly used techniques are:

1. single station Horizontal to Vertical spectral ratio on noise (NHVSR, Nakamura, 1989);

2. single station Horizontal to Vertical spectral ratio on earthquakes (HVSR, Lermo \& Chavez Garcia, 1993);

3. Standard Spectral Ratio (SSR) using a reference site (Borcherdt, 1970).

\subsection{Nakamura technique}

The Nakamura technique consists in performing the spectral ratio between the horizontal and the vertical component of a selected window of background noise recorded at a particular site. Being the seismic noise characterized by a low frequency $(<1 \mathrm{~Hz})$ natural component (ocean storm or meteorological perturbations) and a high frequency $(>1 \mathrm{~Hz})$ anthropic component (Gutenberg, 1958; Asten, 1978), the related analyses allow to obtain information in a broad range of frequency. From a theoretical point of view, considering that the seismic noise is a continuous and stationary phenomena, the spectral analyses have to be computed considering the ratio between the Power Spectral Density (PSD) calculated on each single component for the considered window. In spite of this consideration, also for noise analyses the Fourier spectrum is usually adopted, being easier the direct comparison to earthquake spectra. 
In general noise measurements, being fast and cheap, are usually used for local seismic site response in particular in areas characterized by a low rate of seismicity. The results coming from Nakamura technique have, if possible, to be always supported by further analyses, in particular if the considered site does not show 1D configuration (i.e. non negligible influence of surface waves) or it is characterized by low impedance contrast between bedrock and overlapping soft-layer (usually 4 is considered as a lower bound) or it is characterized by an increase of velocity with depth described by a gradient. Detailed information concerning the data processing that the operator have to follow during noise measurements are provided by the SESAME Project guide line (SESAME, 2003).

\subsection{HVSR technique}

Non reference site technique or single station Horizontal to Vertical Spectral Ratio (Lermo \& Chavez-Garcia, 1993), follows the same idea that is at the base of Nakamura technique: in the case of a soft-layer that overlaps a generic stiff bedrock the incident vertical wave field does not undergo significant modification along the whole source to site path with respect to the horizontal one. In this wave supposing a $1 \mathrm{D}$ configuration of the considered site, the simple ratio between the Fourier spectrum of the horizontal component and Fourier spectrum of the vertical component (both selected on S-phase) allows us to detect the real response of the site (due to the body wave only). The local site response computed by HVSR might be affected by the window selection: in this case longer in time is the S-phase selected window and more probable is the contamination of other phases, in particular if the site does not well reflect a real 1D configuration. The consequence is a contamination of the vertical component that can lead of consequence to an underestimation of the amplification factor. As well as for Nakamura technique, HVSR results, both in terms of frequency and amplification factor have to be verified (if possible) by those coming from techniques based on the reference site.

\subsection{SSR technique}

The Reference site technique or Standard Spectral Ratio (Borcherdt, 1970) is one of the most widely approach used to estimate site effects using earthquake recordings. The site response is evaluated by the ratio between the Fourier spectrum calculated on the horizontal (or vertical) component recorded at a generic site of interest (supposed to be a generic soft soil) and the Fourier spectrum of the same component recorded at the reference site (the outcropping rock is assumed as a generic bedrock). The main difficult concerning this method is, at first, the availability of a good quality reference site (i.e. avoiding for example fractured or weathered rock formations) and, at second, the difficult to have a relevant number of good quality signals recorded at the same time by the stations of interest and by the reference site: usually this condition arose in correspondence of very urbanized areas characterized by a high level of background noise and at the same time by a low rate of seismicity. Of consequence this is the case where it is faster and easier to apply the non reference site technique previous described.

\section{Analyses from seismic noise: Results}

Figure 4 and 5 show examples of results deduced from seismic noise recorded at the considered stations. Data were analyzed by Nakamura technique as explained in the 
previous paragraph. In this case, with the aim to also investigate possible polarization phenomena affecting the wave-field propagation, NHVSRs were calculated rotating the NS component from $0^{\circ}$ to $180^{\circ}$, by step of $5^{\circ}$. In this way for each of the 36 obtained directions the ratio between the Power Spectral Density calculated for the horizontal and for the vertical components were calculated. In the left panels of Figure 4 the directional amplification functions obtained for stations 1 , set on morainic deposits, station 2, set on hundred meters of alluvial deposits, and station 3, installed on rock, are shown. In this case blue and green lines represent the results considering as input seismic noise recorded during winter and summer time respectively. In each panel the single amplification functions represent the average NHVSR calculated considering 120s or 60s signal (for broad band and semi broad band sensors respectively) recorded in different time during the $24 \mathrm{~h}$ (night and day) and in different days of the year (seasonal variations). Each window of signal was processed as explained in the previous paragraph.

Station 1 (Figure 4, top panels), installed in correspondence of a site that approximates enough a 1D configuration, exhibits a clear amplification peak at frequency between 2 and 3 $\mathrm{Hz}$ that (also considering the results showed in the next paragraphs) reflects the site response of the site. On the contrary the very narrow peak at $1 \mathrm{~Hz}$ reflects probably amplification of cultural noise typical of Northern Italy region (Marzorati \& Bindi, 2006). The site does not show preferential direction of amplification (see polar plot in the top right panel of figure 4, but also the low dispersion of amplification functions) and no differences between results obtained considering signals recorded during winter and summer.

On the contrary station 2 (Figure 4, middle panels) shows a low frequency amplification peak (around $0.2 \mathrm{~Hz}$ ) clearly dependent of seasonal cycles, being the peak detected in winter more amplified with respect to the same related to summer: this phenomena is explained with microseisms amplification due to meteorological perturbations during winter (Marzorati \& Bindi, 2006). The right middle panel of figure 4 shows a slight polarization effects at low frequency direction $60^{\circ}-240^{\circ}$.

The station 3 (figure 4 , bottom panels), being installed on rock, does not show particular evidence of amplification.

Station 4 (figure 5, top panels), even if from a geological point of view has characteristic similar to station 3, shows a response that undergoes the influence of topography. One of the main marker for the presence of topographic effects is a strong polarization of the amplification function, more evident if the morphology has a clear 2D configuration. The figure shows two peaks: the first around $5 \mathrm{~Hz}$ clearly polarized in $5^{\circ}-185^{\circ}$ (see the polar plot in the top right panel of figure 5) and the second between $7-8 \mathrm{~Hz}$ without particular preferential directions of amplification. Being the station 4 installed in a tower of an ancient stronghold, as already demonstrated in Massa et al. (2010), the peak around $8 \mathrm{~Hz}$ describes a typical case of interference between ground motion and the vibration of the structure. Bottom panels of Figure 5 depict the results for NRN7 station, located at the top of Narni ridge (central Italian Apennines). In this case distinction between noise recorded during winter and in summer was not possible because of the field experiment was exploited from the end of March to September 2009. However, it is worth mentioning that the long period fluctuations of seismic noise, as demonstrated also from the analyses on station 2, are only detectable in particular configurations (e.g. wide alluvial basin) able to show low frequency responses. On the contrary, topographies are structures that usually are characterized by short predominant period of vibration $(<1 \mathrm{~s})$. 

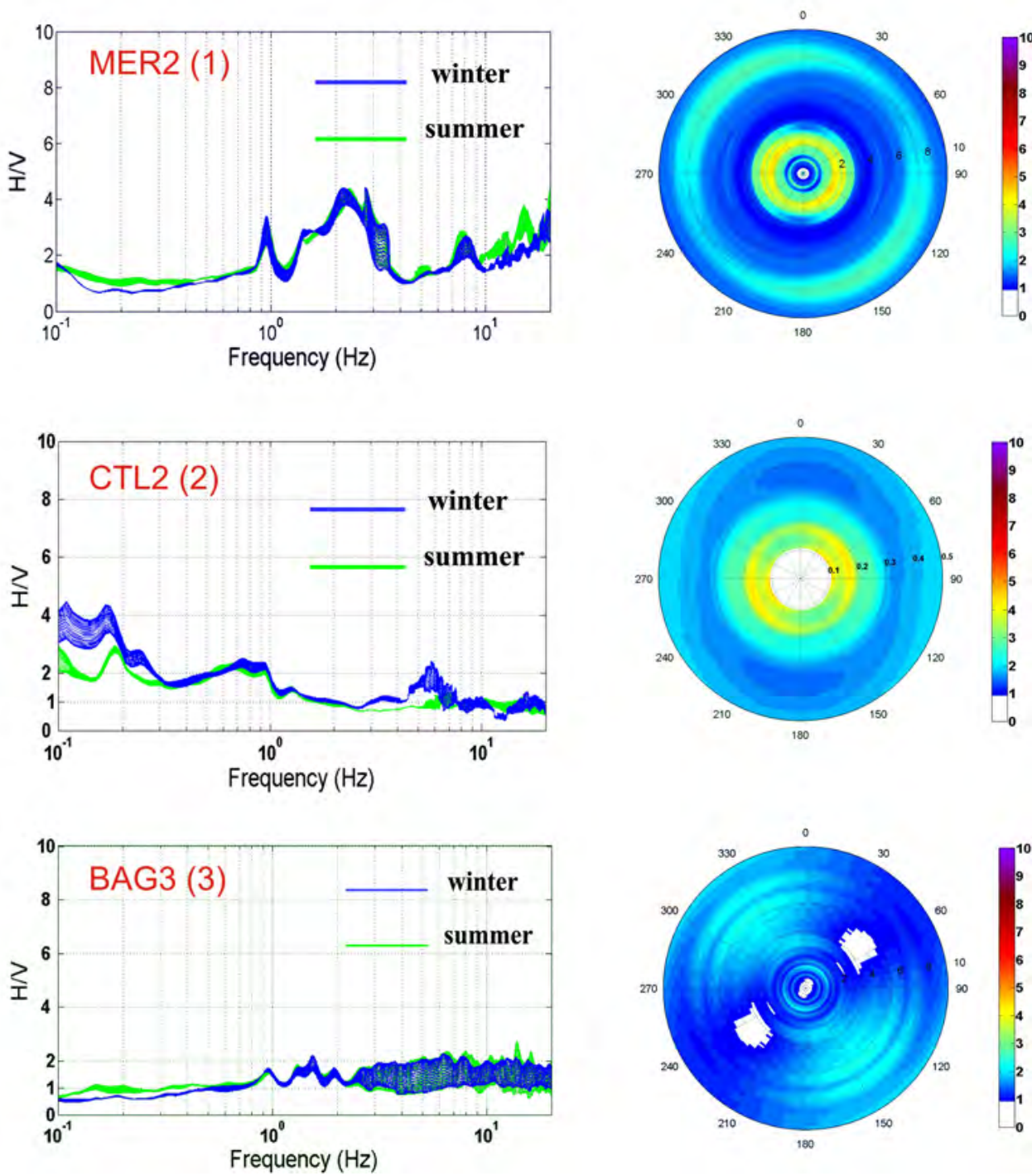

Fig. 4. Left panels: directional NHVSRs for station 1 (morainic deposits), 2 (deep alluvial deposits) and 3 (rock). Blue and green lines represent the average NHVSRs calculated for winter and summer noise recordings. Right panels: corresponding polar plots.

The main evidence for station 5 is a typical response of a $2 \mathrm{D}$ elongated ridge showing an amplification peak around $4 \mathrm{~Hz}$ clearly polarized in EW direction, that represents the azimuth perpendicular to the main elongation of the ridge (NS). 

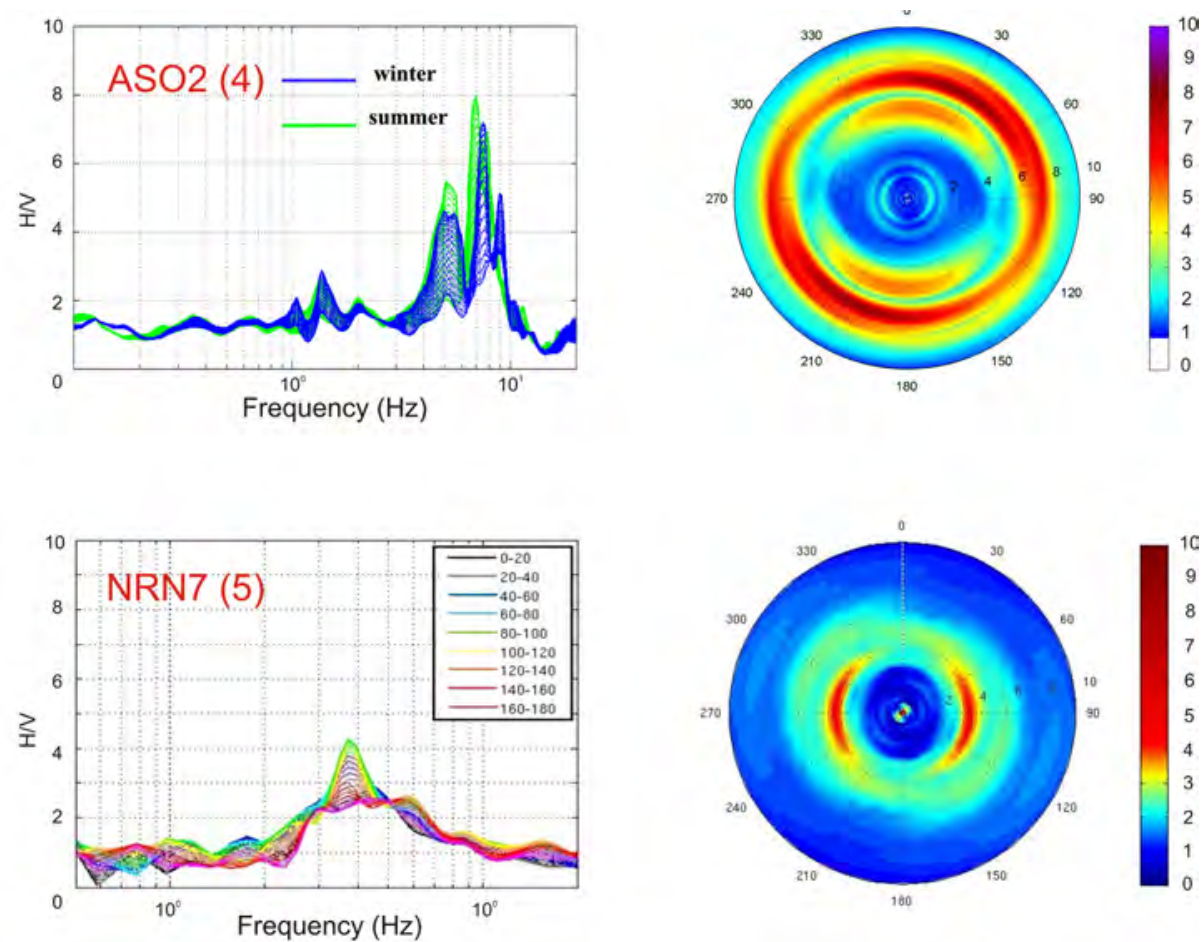

Fig. 5. Left panels: directional NHVSRs for stations 4 (limestone and dolomite 3D hill) and 5 (limestone $2 \mathrm{D}$ ridge). In the top panel blue and green lines represent the average NHVSRs calculated for winter and summer noise recordings, while in the bottom each different colour refer to groups of different directions (step of $20^{\circ}$ ). Right panels: corresponding polar plots.

\section{Analyses from local earthquakes: Results}

In this paragraph HVSR and SSR (only for station 5) results, obtained considering local earthquakes recorded by the four RAIS stations (stations 1, 2, 3 and 4) and by station 5 (NRN7), are presented and discussed in comparison to those obtained from seismic noise analyses.

Figure 6 and 7 show the results, in terms of directional HVSRs, obtained for all analysed stations. In the left panels of figure 6 and in the left top panel of figure 7 each single blue, green and red line represents the average amplification functions (HVSRs) obtained considering windows of $5 \mathrm{~s}$ and $15 \mathrm{~s}$ on S-phase and $20 \mathrm{~s}$ on coda. For each station the data set of events showed in figure 1 and 2 was considered. In particular, the averaged amplification functions were calculated for different azimuths, by rotating the NS horizontal component between $0^{\circ}$ and $180^{\circ}$ (by step of $5^{\circ}$ ).

The bottom left panel of figure 7 is dedicated to the results obtained for station 5 , also in this case showed in term of averaged directional HVSRs calculated on $10 \mathrm{~s}$ of S-phase. All right panels of figure 6 and 7 show the related polar plot calculated for $15 \mathrm{~s}$ of S-phase.

Station 1 (Figure 6, top panels), in agreement to the results obtained from noise analyses, confirms an amplification peak at frequency around $2 \mathrm{~Hz}$ without differences considering 
the three selected windows of signal, even if HVSRs on coda seem to slight underestimate the amplification factor (probable contamination of seismic noise involving the coda). The corresponding polar plot does not show particular preferential directions of amplification.

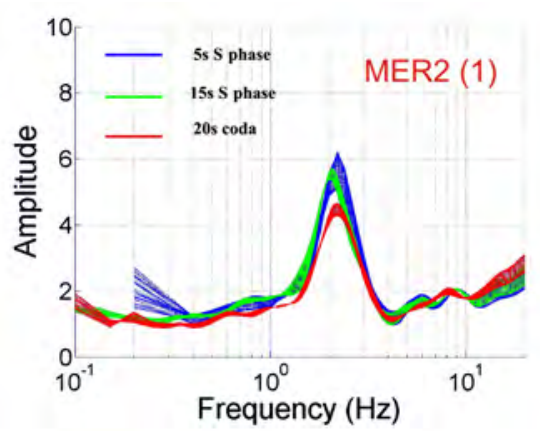

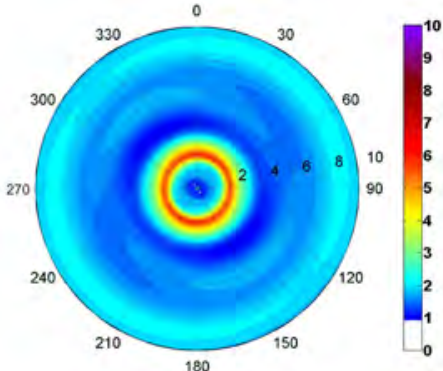

15s S-phase

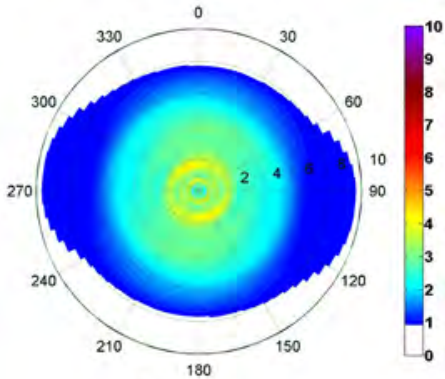

15s S-phase

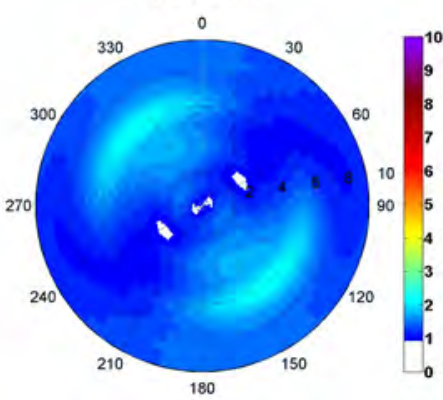

15 s S-phase

Fig. 6. Left panels: directional HVSRs for station 1 (top), 2 (middle) and 3 (bottom) calculated considering $5 \mathrm{~s}$ (blue) and $15 \mathrm{~s}$ (green) of signal selected on S-phase and $20 \mathrm{~s}$ (red) of signal selected on coda. Right panels: polar plots calculated for 15s of S-phase.

More complicated is the interpretation of the results for station 2 (Figure 6, middle panels), installed in correspondence of thick alluvial deposits (the stratigraphy is characterized by an absence of relevant impedance contrasts). In general, in particular considering S-phase selections, the results disagree with those obtained from noise, highlighting the presence of slight broad peak of amplification at frequencies between 1 and $2 \mathrm{~Hz}$. Also in this case the 
analysis on coda shows the lower amplification factors but at the same time is able to reproduce the low frequency peak around $0.2 \mathrm{~Hz}$; considering both the low magnitude of events and the very urbanized area where the station is installed, it is obvious that, being the station characterized by a high level of background noise, the coda of the events is characterized by a predominant percentage of noise itself. In this case the polar plot does not show preferential directions of amplification.

Bottom panels of figure 6 show the results for station 3, that being installed on rock, shows, in agreement to the results obtained from noise analyses, flat HVSRs in the whole frequency range.

Top panels of figure 7 show the results for station 4, installed at the top of a 3D hill. Excluding the peak around $8 \mathrm{~Hz}$, due to the soil-structure interaction (discussed in the previous paragraph), the HVSRs results highlight the presence of two main amplification peaks, the first around $2.5 \mathrm{~Hz}$ and the second, already showed in the noise analyses, at $5 \mathrm{~Hz}$. Concerning the second peak, polarized, as already pointed out from noise, in NS direction $\left(5^{\circ}-185^{\circ}\right)$, the phase selection appears to be not influent on final results. Regarding the peak around $2 \mathrm{~Hz}$ (less polarized), the analysis on coda underestimates, in agreement to the results obtained from noise, the amplification factor and at the same time slightly moves the resonance frequency towards lower frequencies.
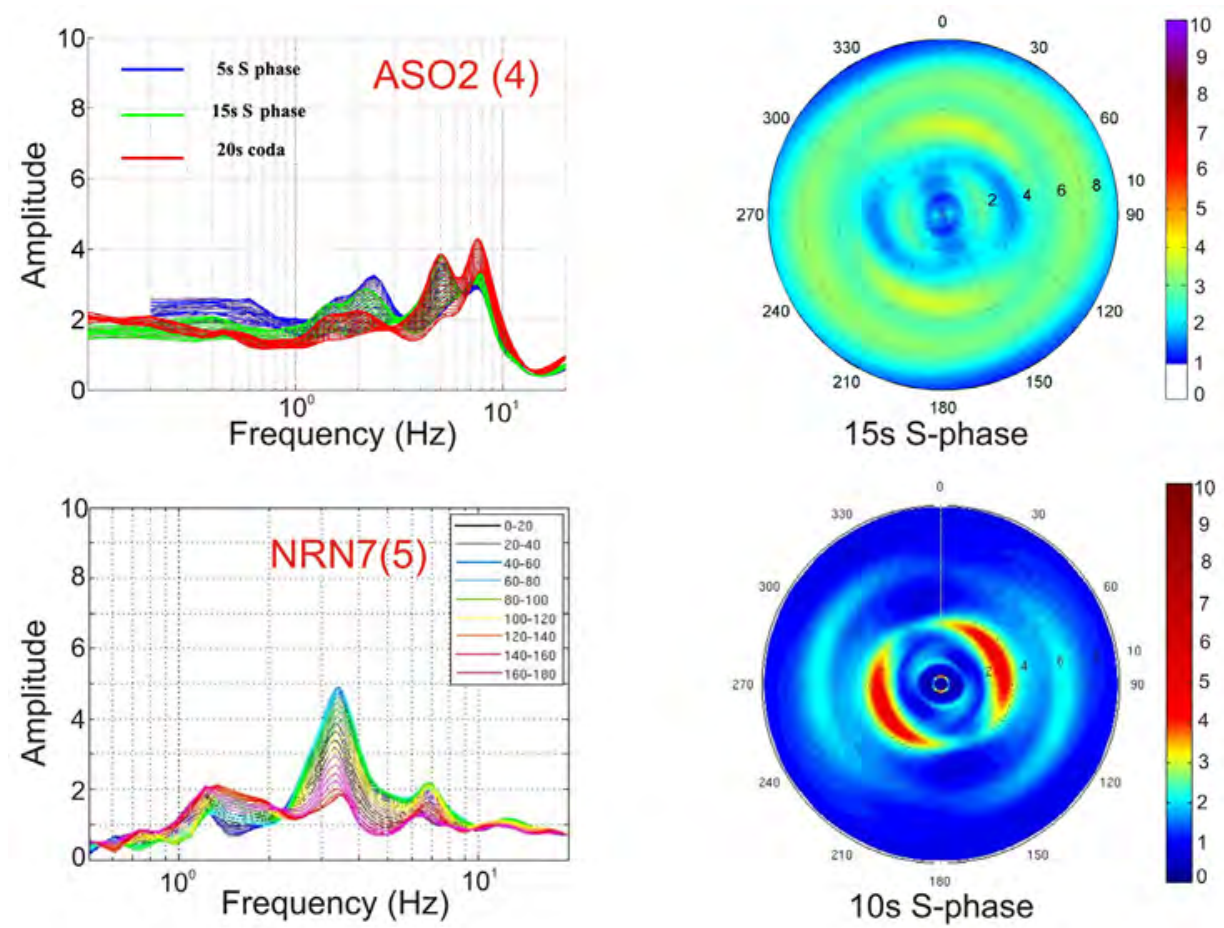

Fig. 7. Top left panels: directional HVSRs for station 4 calculated considering $5 \mathrm{~s}$ (blue) and $15 \mathrm{~s}$ (green) of signal selected on S-phase and $20 \mathrm{~s}$ (red) of signal selected on coda. Top right panels: polar plot calculated at station 4 for $15 \mathrm{~s}$ of S-phase. 
The bottom panels of figure 7 show the results for station 5 (NRN7), installed at the top of a pronounced 2D topography. In this case the main cause for ground amplification is clear and of consequence is not surprising the agreement between the results obtained from noise or earthquakes. Also in this case the figure highlights a clear amplification peak between 3 and $4 \mathrm{~Hz}$ strongly polarized (difference in amplification factors up to 3 ) in the EW direction that is perpendicular to the main elongation of the morphology.

Being Narni ridge monitored by ten temporary velocimetric stations during 2009 (Massa et al., 2010), we have the possibility to compare, at station 5, the HVSR results to those obtained by SSRs technique (in the bottom panel of figure 2 the location of the reference station, NRN2, is shown). Figure 8 shows the SSR results considering for NRN7 (top) and NRN2 (bottom) 29 events with $\mathrm{M}_{\mathrm{L}}$ between 1.5 and 3.6 and epicentral distance up to $30 \mathrm{~km}$.

In this case each SSR curve represents the averaged directional spectral ratio between the Fourier spectra of the considered station and that calculated for the reference (the meaning of the different colours showed in the figure 8 is the same as explained for HVSRs).

As it is possible to note, SSRs highlight the presence of a peak around $2 \mathrm{~Hz}$, not showed by single station HVSR techniques and also a slight shift in frequency, towards higher values, concerning the second peak (between 4 and $5 \mathrm{~Hz}$ ). Also the polarization analyses, even if the higher values are detected for azimuth about perpendicular to the elongation of the ridge, are slightly different with respect to those obtained from HVSRs. In this case, with respect to the other described techniques, being a reference site available and of consequence the amplification functions more approximable to theoretical transfer functions, it is possible to make reliable consideration also about the amplification factor of the site: for the investigated station the amplification value was found to be around 4 .

Bottom left panel: directional HVSRs for stations 5 calculated on $10 \mathrm{~s}$ of $\mathrm{S}$ phase selected considering only events with $\mathrm{M}_{\mathrm{L}}<3$ and distances lower than $50 \mathrm{~km}$ (see bottom panel of figure 2): different colours refer to groups of different directions (step of $20^{\circ}$ ). Bottom right panels: corresponding polar plots.
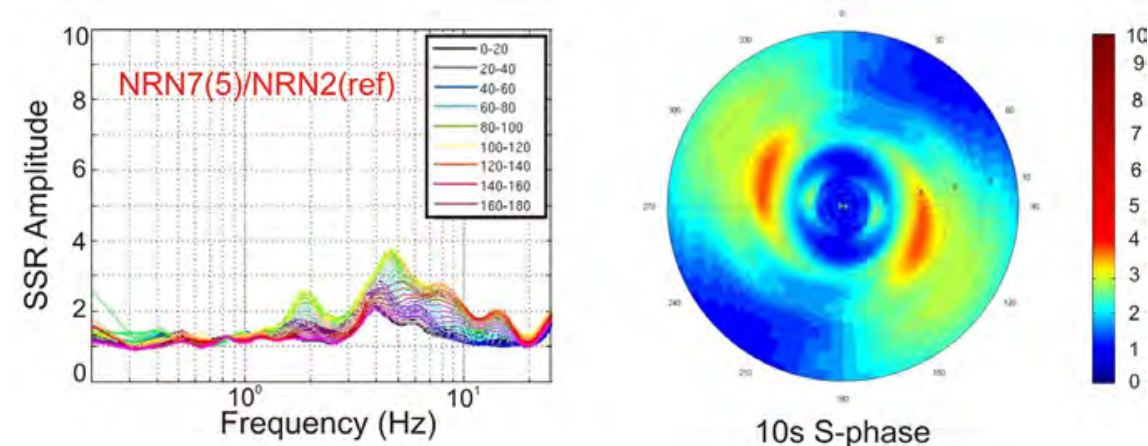

10s S-phase

Fig. 8. Left: directional SSRs performed for station 5 (NRN7) considering 10s of S-phase selected on weak motion ( 29 events with $\mathrm{M}_{\mathrm{L}}$ between 1.5 and 3.6 and epicentral distance up to $30 \mathrm{~km}$ ). NRN2 (see bottom panel of figure 2) is the reference station. Right: related polar plot.

Finally, being the four RAIS stations (1, 2, 3 and 4) characterized both by accelerometric and velocimetric sensors, installed one close to the other, the reliability of a strong-motion sensor 
to evaluate the site response was investigated in term of rotational HVSRs comparing, for station 1, the results obtained using, as input, the recordings coming from different type of instruments. The analyses were computed considering the same data set (figure 1) and the same selection of windows.

Figure 9 shows the HVSR results for station 1 considering the strong motion sensor. In this case, the coupling strong-motion sensor vs. digitizer assuring, in the frequency of interest, a good signal to noise ratio, the HVSR results well reflect those obtained considering the broad band velocimetric sensor (see top panels of figure 6), both in terms of amplified frequency and amplification factors. Also in term of difference among considered phases and polarization effects, in this case the performance of the considered sensor appears to be very similar. In general problem might be arose, in particular at low frequencies, when the same sensor is coupled to digitizer characterized by different dynamic range, as discussed in the following ad-hoc paragraph.
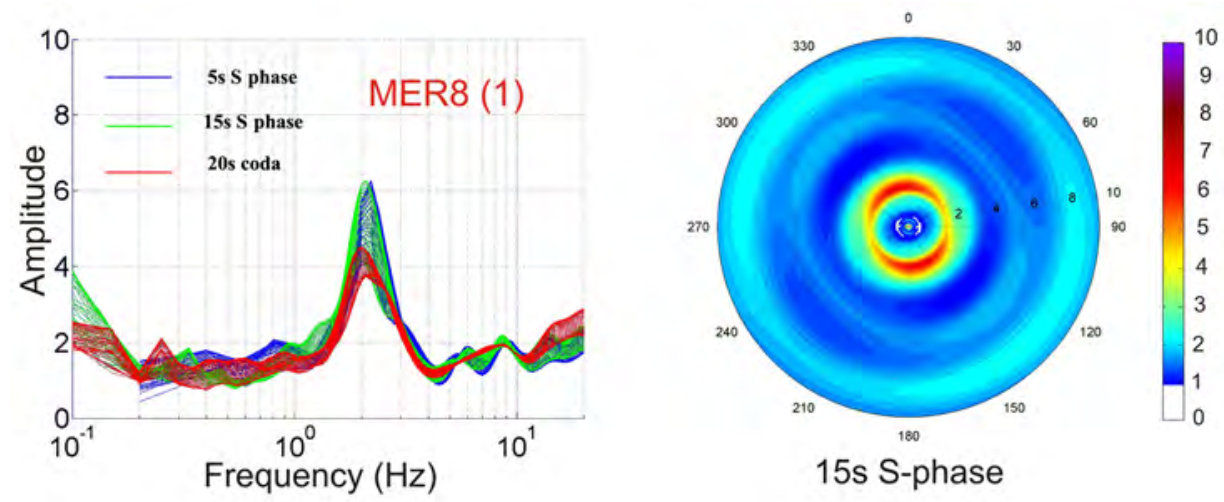

Fig. 9. Left: directional HVSRs calculated for station 1 considering the data set showed in the top right panel of figure 1 but recorded by the strong-motion sensor (Kinemetrics Episensor), for $5 \mathrm{~s}$ (blue) and $15 \mathrm{~s}$ (green) of signal selected on S-phase and $20 \mathrm{~s}$ (red) of signal selected on coda. Right: polar plots calculated for $15 \mathrm{~s}$ of S-phase.

\subsection{Comparison between HVSR and SSR techniques in seismic site evaluation}

Data collected during the Narni experiment (Massa et al., 2010) give us the opportunity to verify the reliability of HVSR and SSR results for site response evaluation. For this purpose we collected a data set composed by the strongest $\left(\mathrm{M}_{\mathrm{L}}>4.0\right.$, see right bottom panel of figure 2) aftershocks of the $6^{\text {th }}$ April 2009, Mw 6.3, L'Aquila mainshock (Ameri et al., 2009). Figure 10 shows a directional HVSRs calculated for the reference station (NRN2, top panel) and for the station 5 (NRN7, bottom panel) and the related directional SSRs (bottom panel). Even in this case amplification functions with different colours indicate all investigated azimuths, as indicated in the legend. This example allows us to point a warning in the use of only techniques without reference site in the estimation of site response. HVSRs reported in the top and middle panel of figure 10 show in particular the presence, for both stations, of a low frequency peak around $0.6 \mathrm{~Hz}$ (see grey area in the figure). The SSR obtained between NRN7 and NRN2 reported in the bottom panel gives completely different results and/or interpretation: the low frequency peak, suffered also by the reference station (that on the 
contrary shows flat response considering noise and local data, non showed here), disappears in the SSR analysis, that, on the contrary well highlights, at station 5, the peak around $4 \mathrm{~Hz}$ due to the topography response, in good agreement to HVSRs computed both on noise and local events (see figures 5 and 7, bottom panels). Even if the interpretation about the origin of the low frequency peak is difficult to explain (probably non correlated to the site response), this example points out a warning about the use of just HVSR (both in frequency and amplitude) in the estimation of site response: the results of a single station analyses can be biased by other phenomena that might mask the real seismic local amplification due to the site.
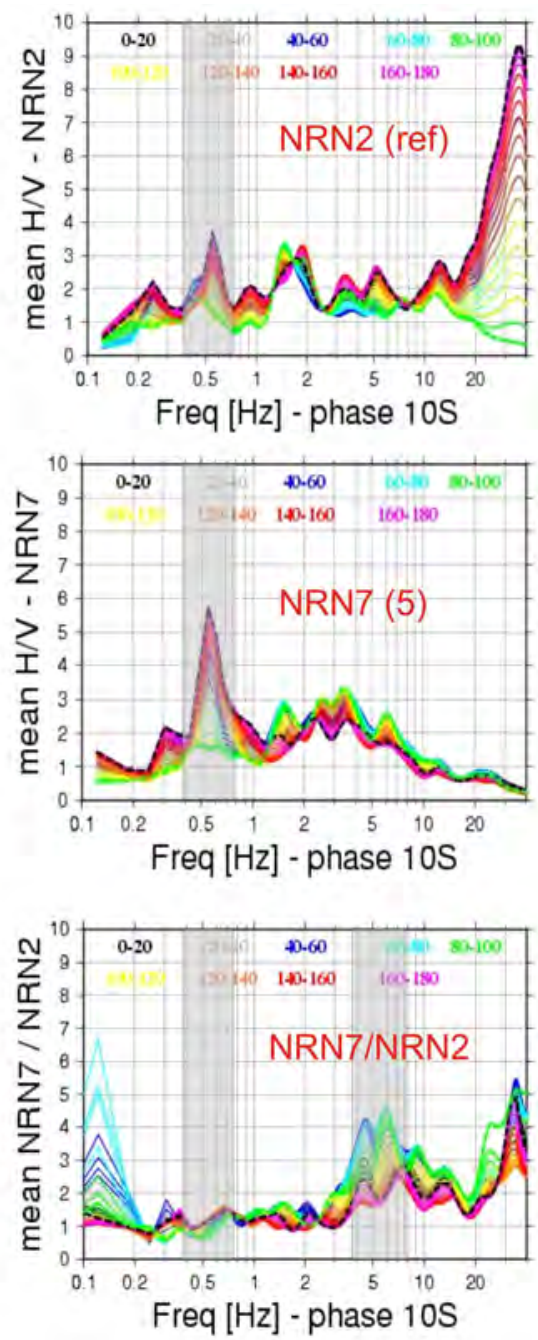

Fig. 10. Directional HVSRs obtained for Narni reference site (NRN2, top panel) and for the investigated station 5 (NRN7, middle panel) and related SSRs (bottom panel). Results were obtained analysing $10 \mathrm{~s}$ of S-phase selected on the strongest aftershock of L'Aquila sequence. 


\section{Analyses from teleseisms: results}

In order to provide further data to use for site response analyses in areas characterized by a low rate of seismicity, HVSRs were calculated also considering the recordings related to four teleseisms: 13 $3^{\text {th }}$ January 2007, Mw 8.2, Kurili earthquake (figure 11, left panel), 25 ${ }^{\text {th }}$ March 2007, Mw 5.8, Greece earthquake, $8^{\text {th }}$ June 2007, Mw 6.2, Greece earthquake (figure 11, right panel), 12 th September 2007, Mw 7.9, Sumatra earthquake. In the last years some papers (Riepl et al., 1998, Dolenc \& Dreger, 2005, Ferretti et al., 2007) demonstrated the capability of teleseisms to well predict the frequency response of a site in the range where the recordings are characterized by a good signal to noise ratio (usually up to about $2 \mathrm{~Hz}$ ). In this way directional horizontal to vertical spectral ratio of teleseismic recordings (calculated by rotating the NS component from $0^{\circ}$ to $180^{\circ}$, by step of $5^{\circ}$ ) are computed selecting $80 \mathrm{~s} \mathrm{P}$ and $S$ phases and the results are compared with the same non-reference site technique applied to local earthquakes (Lermo \& Chavez-Garcia, 1993) and seismic noise (Nakamura, 1989).
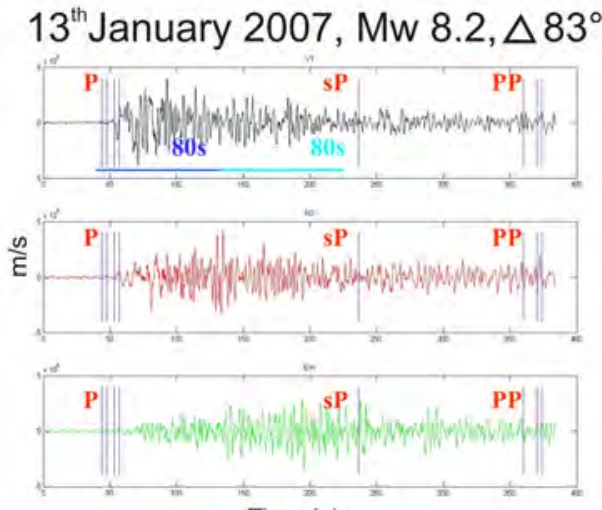

Time (s)
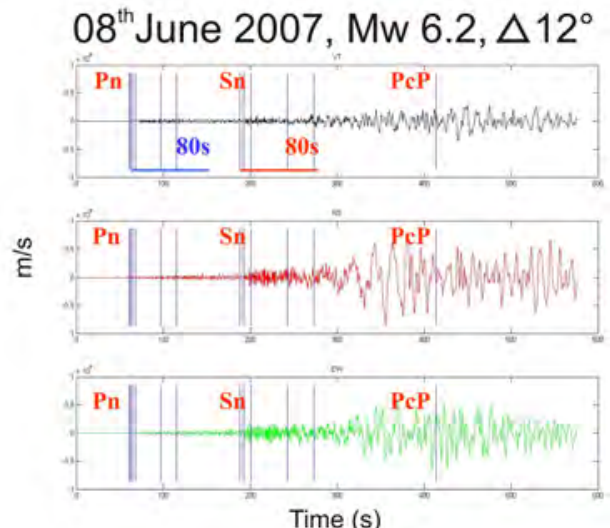

Fig. 11. Teleseismic waveforms (top, middle and bottom are vertical, NS and EW components) related to the $13^{\text {th }}$ January 2007 , Mw 8.2, Kurili earthquake (left) and $8^{\text {th }}$ June 2007, Mw 6.2, Greece earthquake (right) recorded at station 2 by the broad-band sensor (Nanometrics Trillium $40 \mathrm{~s}$ ). The selected portions of windows for HVSR analyses are also indicated.

The HVSR were calculated for station 1 (figure 12, right panels), were a clear target peak was detected both by noise and local events and for station 2 (figure 12, left panels) characterized, in general, by low frequency responses.

In particular one scope was to verify possible improvement concerning the resolution at low frequency $(<1 \mathrm{~Hz})$ for station 2 , installed in the central part of a wide alluvial basin. The processing was computed as well as for noise and local earthquake and also in this case the influence of the azimuth on the amplification was investigated.

Regarding station 2 it is clear as HVSRs calculated on the considered teleseisms well agree to the response obtained by noise and local events: the analyses highlight a clear peak around $2 \mathrm{~Hz}$. In this case considering each single event, it is possible to note that non particular differences are detected considering $\mathrm{P}$ or S-phases. The level of amplification in this case is probably more influenced by each single source to site path. For this site ratio 
higher than $3 \mathrm{~Hz}$ simply reflects the behaviour of background noise. Even in this case the results for station 2 are more complicated, where, on the base of signal to noise ratio, only considerations up to $1.5 \mathrm{~Hz}$ are possible. In this case while Kurili and Sumatra events do not show particular evidences, the two Greece earthquakes better highlight the presence of amplification around $0.2 \mathrm{~Hz}$, detected both on $\mathrm{P}$ and S-phase. In particular, even if the main peak was detected considering the P-phase of the "Greece 1" event, in general considering a broader band of frequency (up to $1 \mathrm{~Hz}$ ), the S-phase for both earthquakes appears more amplified with respect to P-phase (bottom left panel of figure 12).
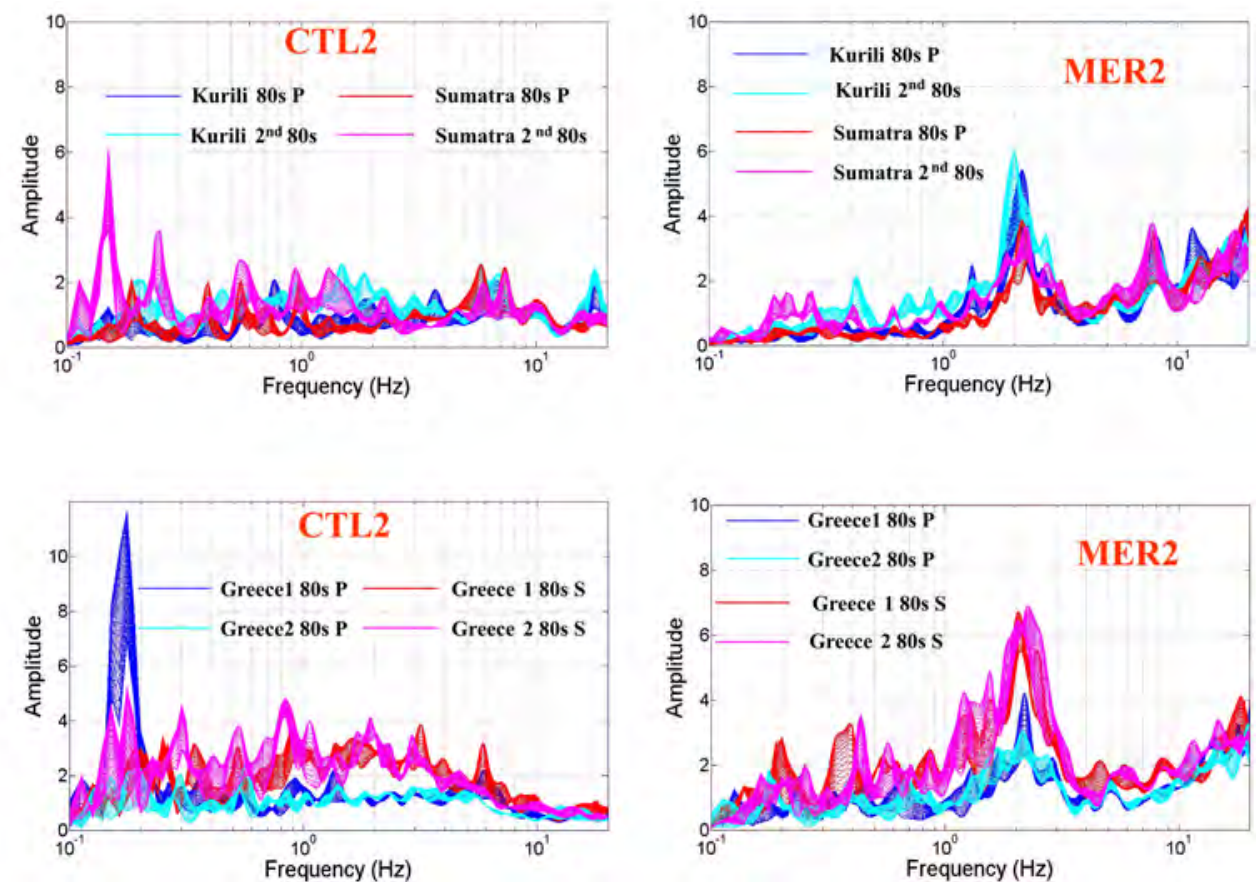

Fig. 12. Directional HVSRs calculated for $13^{\text {th }}$ January 2007, Mw 8.2, Kurili earthquake, for $12^{\text {th }}$ September 2007, Mw 7.9, Sumatra earthquake, for 25th March and $8^{\text {th }}$ June 2007, Mw 5.8 and Mw 6.2, Greece earthquakes (indicated in the bottom panels as "Greece 2" and "Greece 1 " respectively) recorded at stations 2 (left) and 1 (right).

\section{Open issues about site effects evaluation}

In this paragraph the attention is addressed to two common situations that can be encountered during the execution of experimental measurements for site response and consequently can affect the results: the soil structure interaction and the minimum resolution assured by the used instrumentation.

\subsection{Soil-structure interaction}

Soil structure interaction is a phenomenon that arises if the predominant period of vibration of a structure where the seismic sensor is installed covers the frequency response of the 
related site. As demonstrated in Massa et al. (2010) this phenomenon is able to bias the recordings if the sensor is directly connected to the foundation of a building; on the contrary, even if the sensor is installed inside a structure but directly connected to the ground the soil-structure interaction decreases a lot. Concerning the investigated site, station 4, installed at the base of the ancient stronghold gives recordings that show example of soil structure interaction.

The fortress, characterized by a rectangular-shaped with side-length of about 50 and 30m respectively is elongated in the NE-SW direction, very similar to the orientation of the hill (azimuth of about $45^{\circ} \mathrm{N}$ ). Close to the NE corner of the structure is present a tower, where the station 4 is installed.

Figure 13 shows the directional NHVSR obtained from two contemporary seismic noise measurements (at least 30 minutes) performed at the base (in proximity of station 4, Aso-1, green lines) and at the top (Aso-2, blue lines) of the structure. The data processing was performed as explained in the previous paragraphs. On the basis of the results showed for Aso-2 measurement, it is possible to suppose that the ground shaking recorded at the base is probably influenced by the free oscillation of the housing structure, in particular at frequency where no particular polarization phenomena are detected (between 7 and $9 \mathrm{~Hz}$ ). Bottom panels of figure 13 show the polar plots corresponding to Aso-1 (on the right) and Aso-2 (on the left). Aso-2 polar plot highlights directions of preferential amplification polarized in different ways: the first peak, around $5 \mathrm{~Hz}$, in NS direction (it can be also noticed considering the polar plot for Aso-1, on the right), the second, around $7 \mathrm{~Hz}$, about $150^{\circ}-330^{\circ}$ while the third, around $9 \mathrm{~Hz}$, about $90^{\circ}-270^{\circ}$.

\subsection{Comparison between velocimeter and accelerometer}

The second issue regards the minimum resolution that the coupling between a sensor and a digitizer is able to assure. This fact it is important in particular when the site response can be evaluated only by using Nakamura technique. In same cases the instrument resolution is not able to correctly resolve the real background noise (in particular for site characterized by a low level of noise). In order to verify how much the signal recorded by a velocimeter and by an accelerometer performs during noise measurements, station 1, where two 20 bits Lennartz Mars88 are coupled to an accelerometer (Kinemetrics Episensor) and to a broad band sensor (Nanometric Trillium $40 \mathrm{~s}$ ) respectively are installed, was investigated. The Probability Density Function (PDF) of the Power Spectral Density (PSD) of noise window (1 minute long in time) were calculated by Mc Namara \& Buland method (2004) and compared to the Peterson noise curve (figure 14) and the spectra of 5 local weak events recorded in the first $50 \mathrm{~km}$. Figure 14 shows as, only the noise recordings from broad band sensor are able to well reproduce the trend of real background noise at the site while the coupling of a Lennartz Mars88 to a Kinemetrics Episensor is not able to assure at this site reliable noise recordings for frequencies up to $10 \mathrm{~Hz}$. In this range we have clearly recorded the instrumental noise (flat PDF), while for frequencies higher than $10 \mathrm{~Hz}$ the trend is similar to those shown for the coupling digitizer and velocimeter, assuring real noise recordings. Concerning the local events behaviour the figure shows that using accelerometric data we obtain unreliable results for frequencies lower than $1 \mathrm{~Hz}$ : this is the reason for what the HVSR peak at $2 \mathrm{~Hz}$ obtained for station 1 (top panel of figures 6 and 9) is coherent, even if it is calculated using data from weak or strong motion sensor. 


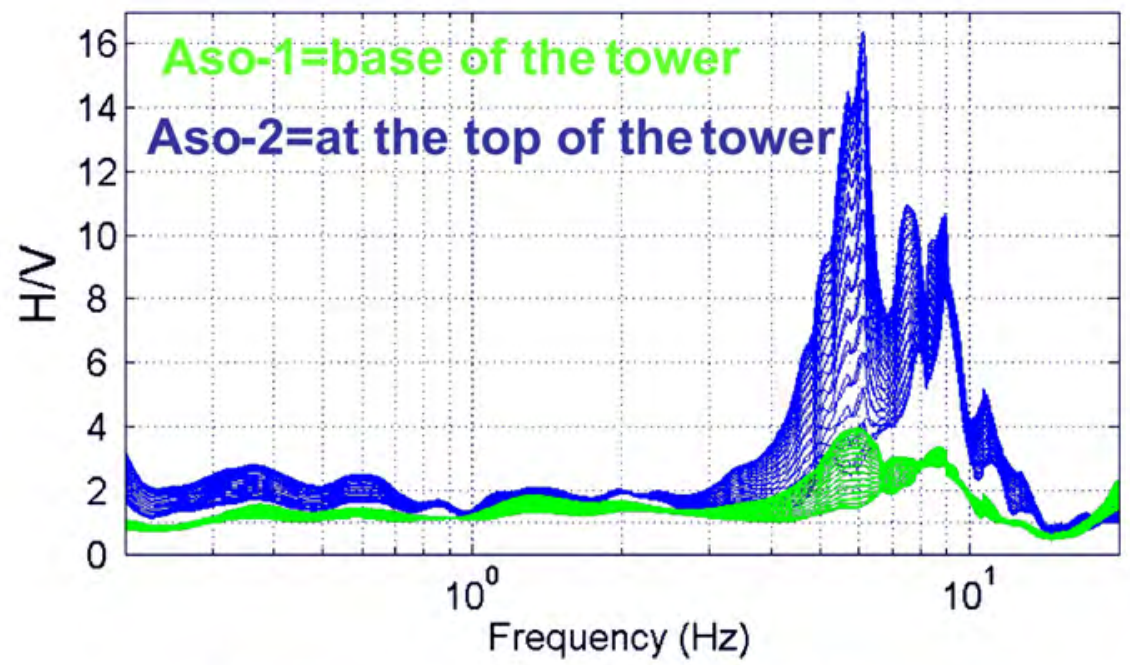

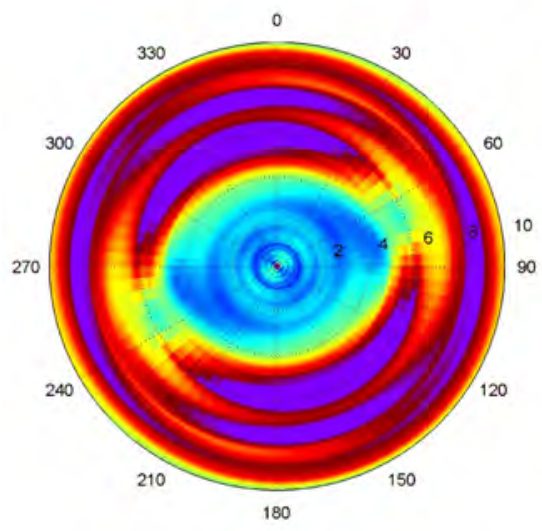

Aso-2

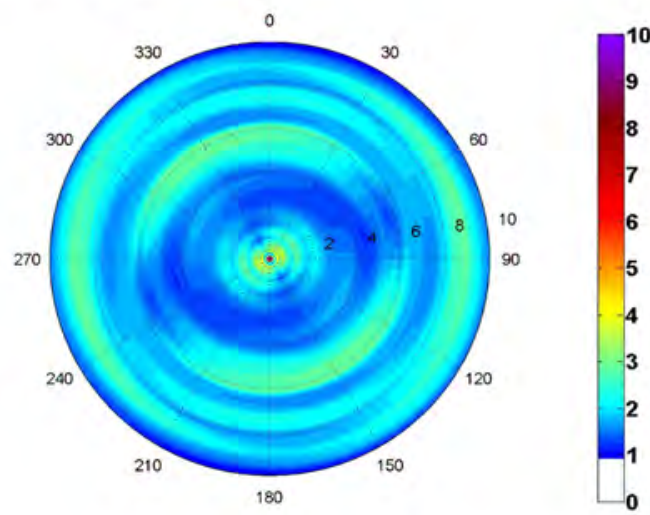

Aso-1

Fig. 13. Top panel: directional NHVSR results obtained from synchronized noise measurements performed, the first (green lines), where the sensors of station 4 are installed (Aso-1, at the base of the tower) and the second (blue lines) at the top of the structure (Aso-2, at the top of the tower). Bottom panels: corresponding polar plots. 

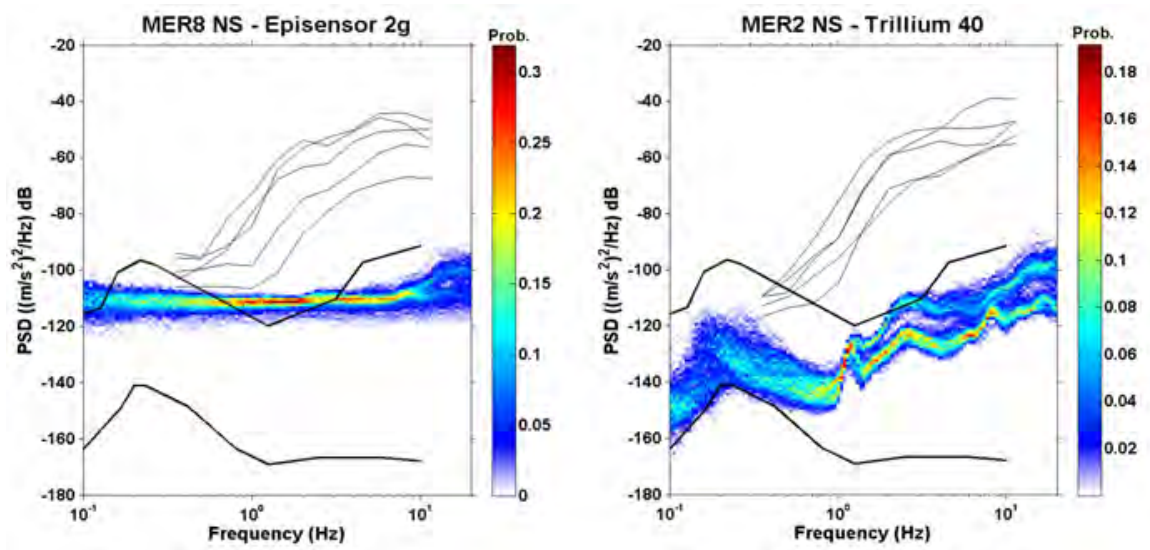

Fig. 14. Probability Density Function calculated averaging Power Spectral Density calculated from many windows of seismic noise ( 1 minute) recorded at station 1 by a Lennartz Mars 88 digitizer coupled to a Kinemetric Episensor (left) and a Nanometrics Trillium 40s (right). In figure also the New High Noise Level and New Low Noise Level Peterson curves are reported (thick black lines). The thin black lines are spectra calculated for weak events selected as example.

\section{Conclusions}

The present chapter focuses the attention on the evaluation of the capabilities of the most common experimental methods used in seismology to estimate the ground motion amplification due to different geological or geomorphological features of a site.

Different techniques were evaluated: single station Horizontal to Vertical Spectral Ratio on noise (Nakamura technique, Nakamura 1989), single station Horizontal to Vertical Spectral Ratio on earthquakes (Lermo \& Chavez Garcia, 1993) and Standard Spectral Ratio technique (Borcherdt ,1970).

While the first two approaches do not take into account a reference site, the last is based on signals contemporary recorded both in the site of interest and in correspondence of a station installed on hard rock (approximably to a bedrock).

In order to investigate a broad frequency responses due to different stratigraphy and morphological setting, 5 Italian sites where seismic stations managed by the Italian National Institute for Geophysics and Volcanology (INGV, department of Milano-Pavia) are installed, were investigated using seismic noise, local (weak motions) and teleseismic events occurred in the last years.

The general considerations, deduced from comparisons made in terms of HVSR and SSR might be summarized as follow:

noise measurements are a cheap and quick tool for seismic site response under particular conditions such as a simple configuration of the site of interest (similar to 1D model) characterized by a high impedance contrast between the soft soil layer and the bedrock (in theory at least $>4$ ).

In general noise measurements give information about the first resonance frequency of the site and tend to underestimate the amplification function obtained from earthquakes (on Sphase) at the same site. 
Amplification functions obtained from noise are more similar to those obtained analyzing the coda of events: in any case no particular consideration about amplification factor is possible in absence of a reference site.

On the basis of the results reported in figure 14, accelerometric sensor is not a good choice for noise analyses, being the results strongly dependent on the available instrumentation.

In a simple configuration and for frequency higher than $1 \mathrm{~Hz}$ there is a good agreement between HVSR results coming from accelerometric and velocimetric data recorded at the same site using the same digitizer. More complicated are the interpretations for stations where possible influence of other phases (i.e. surface waves) are present, such as stations installed in correspondence of alluvial basin.

The good agreement in terms of HVSR obtained comparing local events and teleseisms indicates that for regions characterized by low rate of seismicity, but potentially able to suffer energetic events (such as Northern Italy), the use of teleseisms can give a further improvement to the analyses at low frequency (usually lower than $2 \mathrm{~Hz}$, but however depending on the noise level of each analysed site).

As demonstrated in the example of figure 10, the only use of HVSR, in particular for complicated settings such a topography, can lead to completely biased interpretations: in general, if possible, the use of a reference site technique is strongly encouraged.

If a field experiments is performed in correspondence of urban areas the results can be biased by possible soil-structure interactions, in particular if the sensors are installed inside buildings and directly connected to their foundations.

\section{References}

Amanti, M.; Bontempo, R., Cara, P., Conte, G., Di Bucci, D., Lembo, P., Pantaleone, N.A. \& Ventura, R. (2002). Carta Geologica d'Italia Interattiva 1:100,000 (Interactive geological map of Italy, 1:100,000), SGN, SSN, ANAS, 3cd-rom.

Ameri, G.; Massa, M., Bindi, D., D’Alema, E., Gorini, A., Luzi, L., Marzorati, M., Pacor, F., Paolucci, R., Puglia, R. \& Smerzini, C. (2009). The 6 April 2009, Mw 6.3, L'Aquila (Central Italy) earthquake: strong-motion observations, Seismological Research Letters, Vol. 80, No. 6, pp. 951-966.

Asten, M.W. (1978). Geological control of the three-component spectra of rayleigh-wave microseisms. Bull. Seism. Soc. Am., Vol. 68, No. 6, pp. 1623-1636.

Athanasopoulos, G. A.; Pelikis, P. C. \& Leonidou, E. A. (1999). Effects of surface topography on seismic ground response in the Egion (Greece) 15-6-1995 earthquake. Soil Dynamics and Earthquake Engineering, Vol. 18, No. 2, pp. 135-149.

Bard, P. Y. (1982). Diffracted waves and displacement field over two-dimensional elevated topographies. Geophysical Journal Int. , Vol. 71, No. 3, pp. 731-760.

Bard, P. Y. (1998). Microtremor measurement: a tool for site effect estimation? In: Second International Symposium on the Effects of the Surface Geology on the Seismic Motion, EGS98, Japan.

Bindi, D.; Parolai, S., Spallarossa, D. \& Cattaneo, M. (2000). Site effects by H/V ratio: comparison of two different procedures, J. Earthquake Eng., Vol. 4, No. 1, pp. 97113. 
Borcherdt, R.D. (1970). Effects of local geology on ground motion near San Francisco Bay. Bull. Seism. Soc. Am., Vol. 60, pp. 29-61.

Bordoni, P.; De Rubeis, V., Doumaz, F., Luzi, L., Margheriti, L., Marra, F., Moro, M., Sorrentino, D. \& Tosi, P. (2003). "Geological class map", In: Terremoti probabili in Italia tra l'anno 2000 e 2030: elementi per la definizione di priorità degli interventi di riduzione del rischio sismico, Annex 1, Task 3.2, pp. 3-4, GNDT Proj., Rome.

Caserta, A.; Bellucci, F., Cultrera, G., Donati, S., Marra, F., Mele, G., Palombo, B. \& Rovelli, A. (2000),Study of site effects in the area of Nocera Umbra (Central Italy) during the 1997 Umbria-Marche seismic sequence, J. of Seismology, Vol. 4, No. 4, pp. 555565.

CEN (Comité Européen de Normalisation) (2004). Eurocode 8: Design of structures for earthquake resistanc - Part 5: Foundations, retaining structures and geotechnical aspects. Brussels, Belgium.

Dolenc, D. \& Dreger, D. (2005). Microseismic observations in the Santa Clara Valley, California, Bull. Seism. Soc. Am., Vol. 95, No. 3, pp. 1137-1149.

Donati, S.; Marra, F. \& Rovelli, A. (2001). Damage and ground shaking in the town of Nocera Umbra during Umbria-Marche, central Italy, earthquakes: the special effect of a fault zone. Bull. Seism. Soc. Am., Vol. 91, No. 3, pp. 511-519.

Faccioli, E.; Vanini, M. \& Frassine, L. (2002). “Complex" Site Effects in Earthquake Ground Motion, including Topography. 12th European Conference on Earthquake Engineering, Barbican Centre, London, UK.

Ferretti, G.; Massa, M., Isella, L. \& Eva, C. (2007). Site amplification effects based on teleseismic wave analysis: the case of Pellice Valley (Piedmont, Italy), Bull. Seism. Soc. Am., Vol. 97, No. 2, pp. 605-613.

Géli, L.; Bard, P. Y. \& Jullien, B. (1988). The effect of topography on earthquake ground motion : a review and new results, Bull. Seism. Soc. Am., Vol. 78, No. 1, pp. 4263.

Gutenberg, B. (1958). Microseisms. Advan. Geophys., Vol. 5, pp. 53-92.

Kallou, P.V.; Gazetas, G. \& Psarropoulos, P.N. (2001). A case history on soil and topographic effects in the 7th September 1999 Athens earthquake, Proceedings of 4th Int. Conf. on Recent Advances in Geotechnical Earthquake Engineering and Soil Dynamics, San Diego, California.

Lachet, C. \& Bard, P. Y. (1994). Numerical and theoretical investigations on the possibilities and limitations of Nakamura's technique, J. Phys. Earth, Vol. 42, pp. 377-397.

LeBrun, B.; Hatzfeld, D., Bard, P.Y. \& Bouchon, M. (1999). Experimental study of the ground motion on a large scale topographic hill al Kitherion (Greece), J. of Seismology, Vol. 3, pp. 1-15.

Lermo, J. \& Chavez-Garcia, F. J. (1993). Site effect evaluation using spectral ratio with only one station, Bull. Seism. Soc. Am., Vol. 83, No. 5, pp. 1574-1594.

Lovati, S.; Bakavoli, M.K.H., Massa, M., Ferretti, G., Pacor, F., Paolucci, R., Haghshenas, E. \& Kamalian, M. (2011). Estimation of topographical effects at Narni ridge (Central Italy): comparisons between experimental results and numerical modelling, submitted to Bull. of Earthquake Engineering. 
Marzorati, S. \& Bindi, D. (2006), Ambient noise levels in North-central Italy, Geochem. Geophys. Geosyst., Vol. 7, Q09010, 14 pp., ISSN 1525-2027.

Marzorati, S.; Ladina, C., Falcucci, E., Gori, S., Saroli, M., Ameri, G. \& Galadini, F. (2011). Site effects "on the rock": the case of Castelvecchio Subequo (L'Aquila, Central Italy), Bull. of Earthquake Engineering, Vol. 9, No. 3, pp. 841-868.

Massa, M.; Ferretti, G., Cevasco, A., Isella, L. \& Eva, C. (2004). Analysis of site amplification phenomena: an application in Ripabottoni for the 2002 Molise, Italy, earthquake, Earthquake Spectra, Vol. 20, Issue S1, pp. S107-S118.

Massa, M.; Marzorati, S., Ladina, C. \& Lovati, S. (2010). Urban seismic stations: soil-structure interaction assessment by spectral ration analyses, Bulletin of Earthquake Engineering, DOI 10.1007/s10518-009-9138-1, Vol. 8, No. 3, pp. 723-738.

Massa, M.; Lovati, S., D'Alema, E., Ferretti, G. \& Bakavoli, M. (2010). An experimental approach for estimating seismic amplification effects at the top of a ridge, and the implication for ground-motion predictions: the case of Narni (central Italy), Bull. Seism. Soc. Am., Vol. 100, No. 6, pp. 3020-3034.

McNamara, D.E. \& Buland, R.P. (2004). Ambient noise levels in the Continental Unites States, Bull. Seism. Soc. Am., Vol. 94, No. 4, pp. 1517-1527.

Nakamura, Y. (1989). A method for dynamic characteristics estimations of subsurface using microtremors on the ground surface, Quarterly Rept. RTRI Japan, Vol. 30, pp. 25-33.

NTC (Nuove Norme Tecniche per le Costruzioni) (2008). Part 3: Categorie di sottosuolo e condizioni topografiche, Gazzetta Ufficiale della Repubblica Italiana, No. 29 del 4 febbraio 2008.

Parolai, S.; Bormann, P. \& Milkereit, C. (2001). Assessment of the natural frequency of the sedimentary cover in the Cologne area (Germany) using noise measurements, $J$. Earthquake Eng., Vol. 5, No. 4, pp. 541-564.

Parolai, S.; Richwalski, S.M., Milkereit C. \& Bormann, P. (2004). Assessment of the stability of $\mathrm{H} / \mathrm{V}$ spectral ratios from ambient noise and comparison with earthquake data in the Cologne area (Germany), Tectonophysics, Vol. 390, No. 1-4, pp. 57-73.

Peterson, J. (1993). Observation and modeling of background seismic noise. Open File Report 93-322, USGS, Albuquerque, New Mexico.

Regione Lombardia (2002). Progetto cartografia geoambientale, 1:25000 vers. 1.0.

Regione Lombardia (2003). Progetto cartografia geoambientale, 1:25000 vers. 1.0.

Riepl, L.; Bard, P.Y., Hatzfeld, D., Papaioannou, C. \& Nechtschein, S. (1998). Detailed evaluation of site response estimation methods across and along the sedimentary Valley of Volvi (EURO-SEISTEST), Bull. Seism. Soc. Am., Vol. 88, No. 2, pp. 488502.

Rovelli, A.; Caserta, A., Marra, F. \& Ruggiero, V. (2002). Can seismic waves be trapped inside an inactive fault zone? The case study of Nocera Umbra, central Italy, Bull. Seism. Soc. Am., Vol. 92, No. 6, pp. 2217-2232.

SESAME, Site Effects Assessment Using Ambient Excitations (2003). European Commission Research General Directorate. Project No. EVG1-CT-2000-00026 SESAME. Final report WP08 - Nature of noise wavefield. 
Strollo, A.; Richwalski, S. M., Parolai, S., Gallipoli, M. R., Mucciarelli, M. \& Caputo, R. (2007). Site effects of the 2002 Molise earthquake, Italy: analysis of strong motion, ambient noise, and synthetic data from 2D modelling in San Giuliano di Puglia, Bull. Earth. Eng., Vol. 5, No. 3, pp. 347-362. 